\title{
APPLYING MASS TRANSFER MODELS FOR CONTROLLING ORGANIC COMPOUNDS IN OZONATION PROCESS
}

\author{
Pen-Chi Chiang, Ya-Wen Ko*, and Yao-Ming Yang \\ Graduate Institute of Environmental Engineering, National Taiwan University, Taipei, Taiwan, \\ ROC \\ E.E. Chang \\ Department of Analytical Chemistry, Taipei Medical College, Taipei, Taiwan, ROC
}

EI 9612-268 M (Received 30 December 1996; accepted 5 August 1997)

\begin{abstract}
Mass transfer plays a significant role in the ozonation process. The prediction models associated with the volumetric overall mass transfer coefficient $\left(\mathrm{K}_{\mathrm{L}} \mathrm{a}\right)$ and initial fractional ozone absorption $\left(\mathrm{FOA}_{0}\right)$ during the ozonation process were developed through the use of dimensional analysis. It was found that the volumetric overall mass transfer coefficient is the function of diffusivity, agitation speed, and gas flow rate, and the parameters in the $\mathrm{K}_{\mathrm{L}} \mathrm{a}$ equation are determined. Application of the prediction models for $\mathrm{K}_{\mathrm{L}} \mathrm{a}$ and $\mathrm{FOA}_{0}$ would yield information to choose the most practically feasible operating parameters. The removability of total organic carbon (TOC) can be estimated based on the mass balance relationship and kinetic expression of TOC oxidation, during continuous laboratory ozonation of humic acid solution. The reaction rate constant averaged $0.0291 \mathrm{~L} / \mathrm{mg} \cdot \mathrm{min}$. The developed model in combination with the mass transfer and reaction kinetics can be used successfully in forecasting the most efficient agitation speed to control the formation of organic compounds. Also, the critical value of ozone partial pressure to achieve the highest TOC removability can be determined through the use of the above developed model. O1997 Elsevier Science Lid
\end{abstract}

\section{INTRODUCTION}

In Taiwan, chlorination is the most extensively used technique for disinfecting drinking water in the water treatment process. However, disinfection of water by chlorine can lead to the formation of organic halides and disinfection by-products, some of which have adverse toxicological effects on human health. There is an increasing interest in the use of ozone because it has a higher oxidation potential for reduction of dissolved organic substances than chlorine. During the ozonation process, ozone gas is usually brought into continuous

*Corresponding author: Ya-Wen Ko, 71, Chou-Shan Rd., Graduate Institute of Environmental Engineering, National Taiwan University, Taipai 106, Taiwan, ROC. contact with water under dynamic conditions. Since mass transfer of ozone is generally the rate-determiningstep concerning the mechanisms of ozone reaction, factors including water qualities and operational parameters affecting mass transfer should be examined.

The mass transfer rate is influenced by operating variables such as $\mathrm{pH}$, temperature, agitation speed, and gas flow rate (Sotelo et al. 1989). According to Sheffer and Esterson (1982), $\mathrm{K}_{\mathrm{L}} \mathrm{a}$, the volumetric overall mass transfer coefficient of ozone in tap water, was about $1.14 \mathrm{~min}^{-1}$ and reached a higher value at a higher water flow rate. There was a large decrease in $\mathrm{K}_{\mathrm{L}} \mathrm{a}$ to $0.250 \mathrm{~min}^{-1}$ without agitation. Sheffer and Esterson (1982) reported that there was a linear relationship. 


\section{NOMENCLATURE}

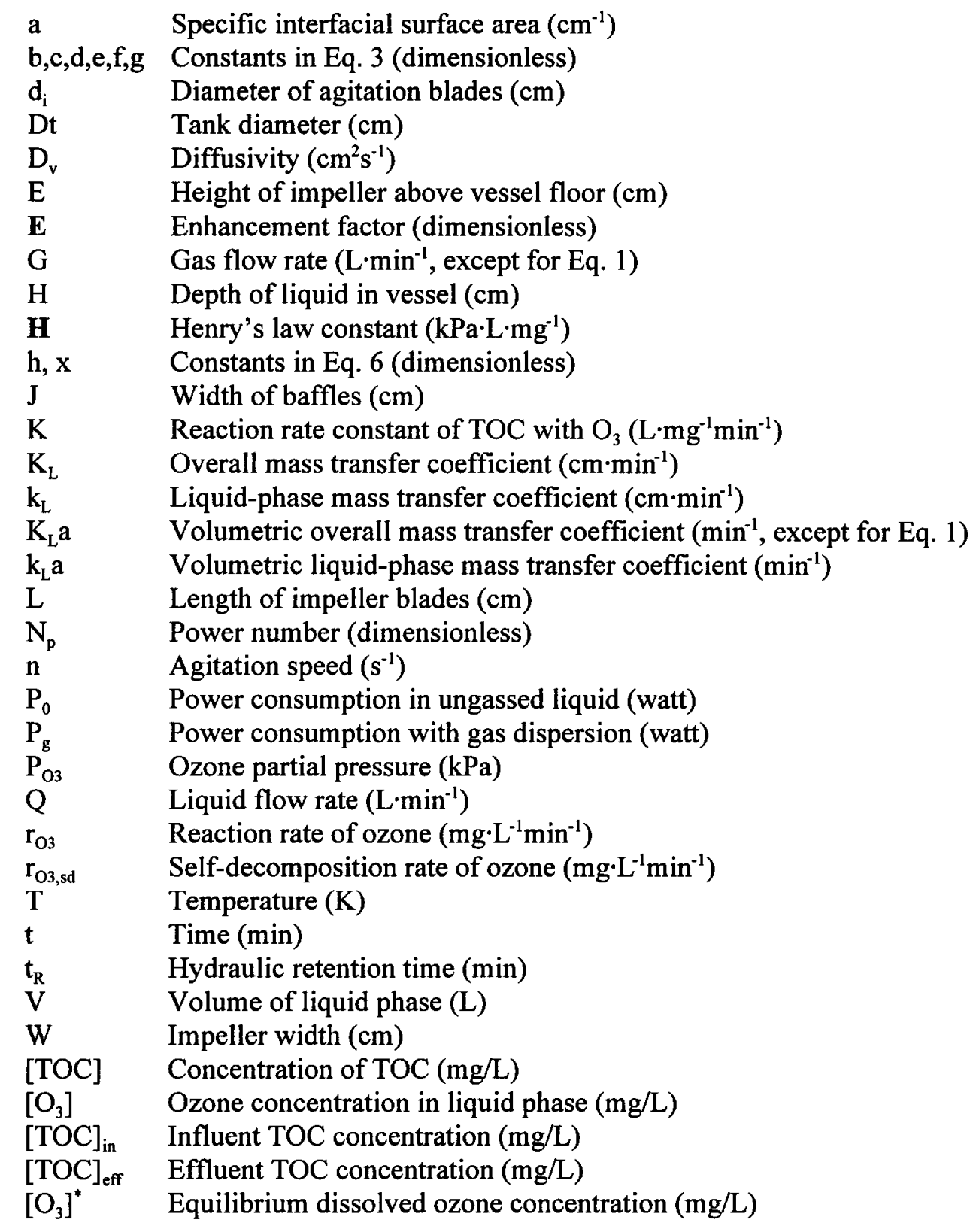

\section{Greek letters}

$\begin{array}{ll}\alpha & \text { Ratio of } \mathrm{P}_{\mathrm{g}} \text { over } \mathrm{P}_{0} \text { (dimensionless) } \\ \mu & \text { Viscosity }\left(\mathrm{g} \cdot \mathrm{cm}^{-1} \mathrm{~s}^{-1}\right) \\ \rho & \text { Density }\left(\mathrm{g} \cdot \mathrm{cm}^{-3}\right)\end{array}$

between the ozone feed rate and ozone residual. Water flow rate, gas flow rate, and temperature determined the slope and the intercept of the linear function.

Some semi-empirical regressions of $\mathrm{K}_{\mathrm{L}}$ a have been reported (Grasso 1987; Ouederni et al. 1987; Stankovic
1988). Ouederni et al. (1987) proposed the following equation to relate the ozone transfer in stirred reactors:

$$
\mathrm{K}_{\mathrm{L}} \mathrm{a}=2.57 \times 10^{-2} \times(\mathrm{G} \times \mathrm{n})^{0.67}
$$


where,

$\mathrm{K}_{\mathrm{L}} \mathrm{a}$ is expressed in $\mathrm{s}^{-1}$;

$\mathrm{G}$ is the gas flow rate expressed in $10^{-3} \mathrm{~m}^{3} / \mathrm{s}$; and,

$\mathrm{n}$ is the number of rotations per second.

Previous investigators (Roth et al. 1982; Gurol 1985; Benitez et al. 1991) incorporated mass transfer and kinetics with operating parameters for scale-up of the ozonation process and to study the removal efficiency of the target compound. The resulting model proposed by Roth et al. (1982) included the mass transfer intrusion originating from the diffusional resistance of ozone and the complex kinetics encountered during ozonation, and can be applied to both semi-batch mode and CSTR mode operations. Benitez et al. (1991) studied the reaction between ozone and MCPA, a pesticide included in the group of the phenoxyalkyl acid derivatives, and concluded that both the gas flow rate and the agitation speed had a positive effect on the MCPA degradation.

The main objective of this study was to develop the prediction models associated with the mass transfer characteristic of the ozonation system, and to choose the most practically feasible operating parameters to reduce organic compounds. First, the prediction equation of $\mathrm{K}_{\mathrm{L}}$ a was derived through the use of dimensional analysis. Then, the parameters in the equation were determined using the experimental data. The removability of total organic carbon (TOC) was estimated based on the mass balance relationship and kinetic expression of TOC oxidation, during the continuous laboratory ozonation of humic acid solution. Also, the reaction rate constant was determined from the experimental data. In conjunction with the semi-empirical equation of $\mathrm{K}_{\mathrm{L}} \mathrm{a}$ and TOC reaction kinetics, this ozone mass transfer model can provide the most efficient agitation speed required to control the formation of organic compounds.

\section{MATERIALS AND METHODS}

\section{Ozone contacting system}

As shown in Fig. 1, a laboratory-scale ozonation system, including a $15 \mathrm{~L}$ stainless steel reactor, a cylindrical vessel with a built-in diffuser for ozone introduction, a flat-bladed turbine with six blades, and four internal baffles to facilitate mixing was used in this investigation. The design of reactor was based on the criteria of shape factors for a standard six-bladed turbine (McCabe et al. 1985): $d_{i} / D t=1 / 3, E / d_{i}=1$, $\mathrm{L} / \mathrm{d}_{\mathrm{i}}=1 / 4, \mathrm{~W} / \mathrm{d}_{\mathrm{i}}=1 / 5, \mathrm{~J} / \mathrm{Dt}=1 / 12$, and $\mathrm{H} / \mathrm{Dt}=1$, as shown in Fig. 1. Ozone generated from pure oxygen, along with the carrier gas, was admitted to the reactor in a semi-batch or continuous mode. All fittings, valves, and tubing were of stainless steel, glass, or Teflon.

\section{Analytical methods}

TOC analysis was performed using a TOC analyzer (Model 700, O.I. Corp.) and calibrating with potassium hydrogen phthalate. Dissolved ozone concentration was determined by the indigo method (Bader and Hoigne 1981), while the gaseous ozone concentration was quantified by absorbing in potassium iodide traps and subsequently titrating with sodium thiosulfate solution.

\section{Experimental methods}

Before starting absorption and/or reaction, the ozoneoxygen stream was directed into a KI solution to analyse gaseous ozone concentration. When the desired ozone concentration was reached, the gas stream was fed into the reactor. In the physical absorption experiments, the phosphate salts (disodium hydrogen phosphate and potassium dihydrogen phosphate) were added into deionized water (Milli-Q SP) to maintain a $\mathrm{pH}$ of 5 or 7 and ionic strength of $0.015 \mathrm{M}$. The absorption process was carried out, in a semi-batch mode, until a steady state concentration of dissolved ozone was reached. The synthetic samples prepared by humic acids (Wako Pure Chemical Industries) and phosphate salts (the same as the physical absorption experiments) were introduced to run the TOC reduction tests, which were conducted in a continuous mode.

\section{RESULTS AND DISCUSSION}

\section{Model development}

Semi-empirical equation of $K_{L} a$. The following assumptions were made to derive the appropriate model for prediction of $\mathrm{K}_{\mathrm{L}} \mathrm{a}$ :

1) Higbie's penetration theory is applied to correlate the relationship between the overall mass transfer coefficient, $\mathrm{K}_{\mathrm{L}}$, and diffusivity.

2) Liquid-phase mass transfer coefficient, $k_{L}$, is equal to overall mass transfer coefficient, $\mathrm{K}_{\mathrm{L}}$, when the gasside resistance is comparatively neglected.

3) Influent gas flow rate is irrelevant to the overall mass transfer coefficient, $K_{L}$.

4) Temperature and agitation speed are irrelevant to a, the specific interfacial surface area.

Although the agitation speed and temperature may influence the gas bubble diameter, and therefore the specific interfacial area, the dependence of the specific inter- 


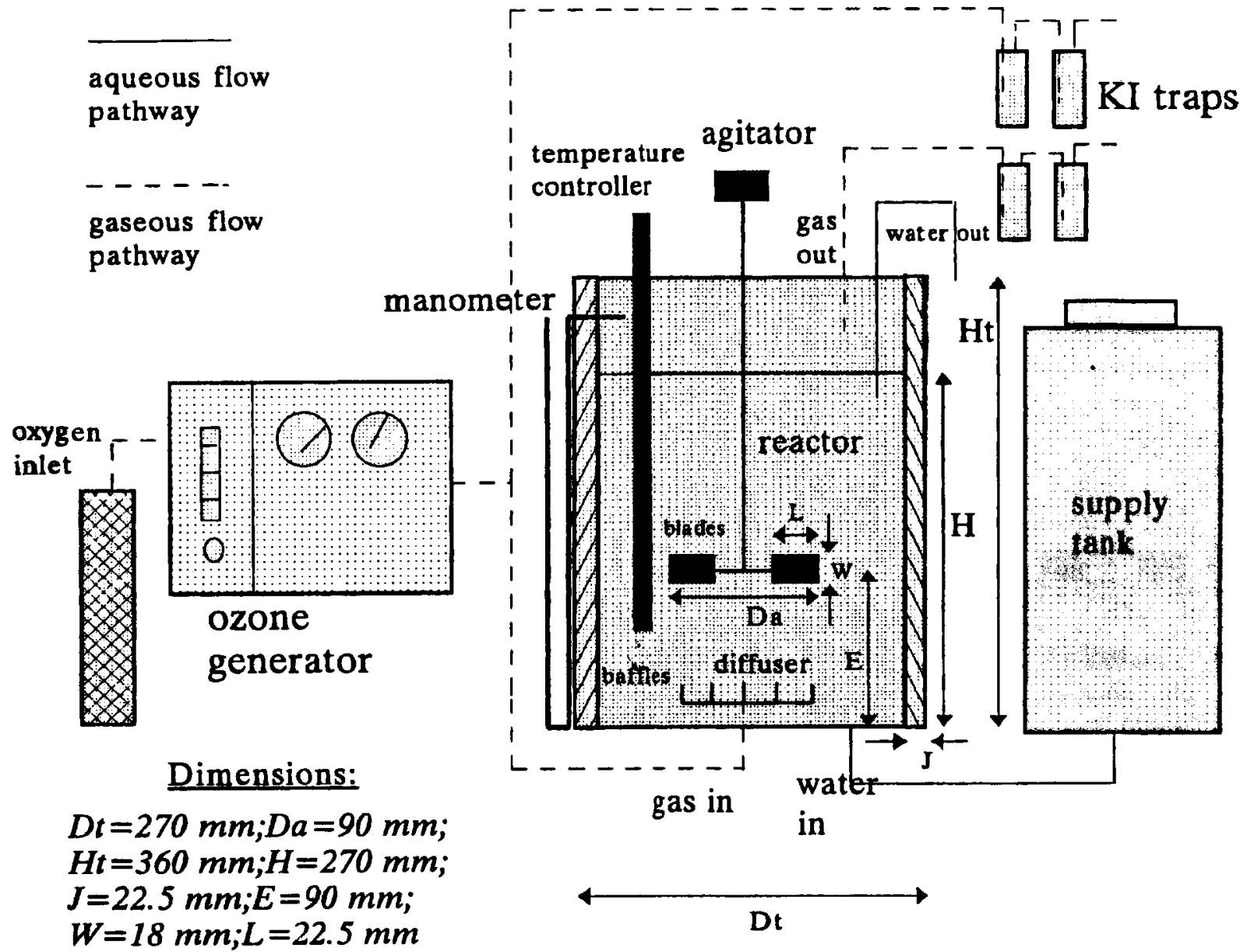

Fig. 1. Schematic diagram of ozone experimental system.

facial area on the gas flow rate is much stronger. Therefore, hypothesis (4) is a reasonable assumption, which greatly simplifies the model development process.

According to the mechanism of mass transfer, $K_{L}$ is a function of diffusivity $\left(D_{v}\right)$, viscosity $(\mu)$, density $(\rho)$, and characteristics of liquid flow, which can be given by the velocity of the tip of agitation blades, $\pi \mathrm{nd}_{\mathrm{i}}$, where $d_{i}$ is the diameter of agitation blades and $n$ is the agitation speed. Therefore, the relationship between the variables affecting $\mathrm{K}_{\mathrm{L}}$ can be written as:

$$
\mathrm{K}_{\mathrm{L}}=\mathrm{f}\left(\mathrm{D}_{\mathrm{v}}, \mu, \rho, \mathrm{nd}_{\mathrm{i}}\right)
$$

Equation 2, including six variables and three fundamental quantities (mass, length, and time), can be regarded as the sum of a number of terms each consisting of products of powers of the variables.

$$
K_{L}=g\left(D_{v}\right)^{f}(\mu)^{b}(\rho)^{c}(n)^{d}\left(d_{i}\right)^{e}
$$

where $b, c, d, e, f$, and $g$ are constants.

These can be expressed in terms of mass, length, and time as follows:

$$
\begin{aligned}
& \mathrm{K}_{\mathrm{L}}=\mathrm{LT}^{-1} ; \mathrm{D}_{\mathrm{v}}=\mathrm{L}^{2} \mathrm{~T}^{-1} ; \mu=\mathrm{ML}^{-1} \mathrm{~T} \\
& \rho=\mathrm{ML}^{-3} ; \mathrm{n}=\mathrm{T}^{-1} ; \mathrm{d}_{\mathrm{i}}=\mathrm{L}
\end{aligned}
$$

Based on Buckingham's $\pi$ Theorem, the number of dimensionless groups will be three. The conditions of dimensional consistency must be met for each of the fundamentals and the orders of each of these variables can be equated. After substitution and calculation, the following equation can be expressed:

$$
\frac{K_{L} d_{i}}{D_{\nu}}=\left(\frac{n d_{i}^{2} \rho}{\mu}\right)^{1-f-b}\left(\frac{\mu}{D_{\nu} \rho}\right)^{1-f} n^{2 b}
$$


Three dimensionless groups, $\mathrm{K}_{\mathrm{L}} \mathrm{d}_{\mathrm{i}} / \mathrm{D}_{\mathrm{v}}, \mathrm{nd}_{\mathrm{i}}{ }^{2} / \mu, \mu / \mathrm{D}_{\mathrm{v}} \rho$, known as the Sherwood number, Reynolds number, and Schmilt number, respectively, were generated.

Higbie's penetration theory indicates that $\mathrm{K}_{\mathrm{L}}$ is proportional to $D_{v}{ }^{0.5}$. Substitution of this relationship and the condition of dimensional consistency in Eq. 4 resulted in the following:

$$
\mathrm{K}_{\mathrm{L}}=\mathrm{D}_{\mathrm{v}}^{0.5} \mathrm{n}^{0.5}
$$

On the other hand, combining the empirical relationship reported by Stankovic (1988) with Eq. 5 yielded the following equation:

where,

$$
\mathrm{K}_{\mathrm{L}} \mathrm{a}=\mathrm{hD}_{\mathrm{v}}^{0.5} \mathrm{n}^{0.5} \mathrm{G}^{\mathrm{x}}
$$

$\mathrm{h}, \mathrm{x}$ are constants;

$\mathrm{a}=$ specific interfacial area, $\mathrm{cm}^{-1} ;$ and, $\mathrm{G}=$ influent gas flow rate, $\mathrm{L} / \mathrm{min}$.

$$
\frac{d[T O C]}{d t}=-K[\text { TOC }]\left[O_{3}\right]
$$

Removal of TOC in ozone reaction. The reaction of ozone with organic compounds usually conforms to a first-order kinetic expression with respect to both the concentration of ozone and that of organic compounds. The humic acids solution in terms of TOC was chosen as the target compound to determine the removal efficiency of ozone. Thus, the following expression was obtained:

where,

$[\mathrm{TOC}]=$ concentration of $\mathrm{TOC}, \mathrm{mg} / \mathrm{L}$;

$\mathrm{t}=$ time, $\mathrm{min}$;

$\mathrm{K}=$ reaction rate constant, $\mathrm{L} / \mathrm{mg} \cdot \mathrm{min}$; and,

$\left[\mathrm{O}_{3}\right]=$ ozone concentration in liquid phase, $\mathrm{mg} / \mathrm{L}$.

The mass balance equation for TOC in continuous operation can be described as follows:

where,

$$
Q[T O C]_{i n}=V\left(-\frac{d[T O C]}{d t}\right)+Q[T O C]_{e f f}
$$

$\mathrm{Q}=$ liquid flow rate, $\mathrm{L} / \mathrm{min}$;

$[\mathrm{TOC}]_{\mathrm{in}}=$ influent TOC concentration, $\mathrm{mg} / \mathrm{L}$;

$[\mathrm{TOC}]_{\mathrm{eff}}=$ effluent $\mathrm{TOC}$ concentration, $\mathrm{mg} / \mathrm{L}$; and, $\mathrm{V}=$ volume of liquid phase, $\mathrm{L}$.

$$
\frac{[T O C]_{e f f}}{[T O C]_{i n}}=\frac{1}{t_{R} K\left[O_{3}\right]+1}
$$

Substitution of Eq. 7 into Eq. 8 yielded the following equation:

where $t_{R}=$ hydraulic retention time $=V / Q$, min.

\section{Parameters identification}

Determination of parameters in the $K_{L}$ a prediction equation. To demonstrate the application of Higbie's penetration theory to this experimental system, the linear regression of $K_{L} a$ vs $D_{v}{ }^{0.5}$ was examined and is shown in Fig. 2. In Fig. 2, $D_{v}$ was calculated by Wilke and Chang's correlation; while $\mathrm{K}_{\mathrm{L}} \mathrm{a}$ and equilibrium dissolved ozone concentration $\left(\left[\mathrm{O}_{3}\right]^{*}\right)$ were obtained from the following mass balance equation:

$$
\frac{d\left[O_{3}\right]}{d t}+r_{03, s d}=K_{L} a\left(\left[O_{3}\right]^{*}-\left[O_{3}\right]\right)
$$

where $r_{03, s d}=$ self-decomposition rate of ozone. This can be described by (Yang 1991):

$$
\begin{gathered}
r_{03, s d}=5.117 \times 10^{10} \exp \left(-\frac{8835.25}{T}\right)\left[O_{3}\right] \\
+9.207 \times 10^{16} \exp \left(-\frac{8835.25}{T}\right)\left[O H^{-}\right]^{0.5}\left[O_{3}\right.
\end{gathered}
$$

where $\mathrm{T}=$ temperature, $\mathrm{K}$.

With the known $\left[\mathrm{O}_{3}\right]$ and $\mathrm{t}$, as well as $\mathrm{r}_{\mathrm{O} 3 \text {,sd }}, \mathrm{K}_{\mathrm{L}}$ a and $\left[\mathrm{O}_{3}\right]^{*}$ were determined through the use of a linear regressionanalysis under specific experimental conditions.

Substitution of 20 sets of experimental results into Eq. 6 led to the prediction model of $\mathrm{K}_{\mathrm{L}} \mathrm{a}$, by the use of non-linear regression analysis:

$\mathrm{K}_{\mathrm{L}} \mathrm{a}=1.20 \times \mathrm{D}_{\mathrm{v}}^{0.5} \mathrm{n}^{0.5} \mathrm{G}^{1.18}+0.027, \mathrm{R}^{2}=0.964$

where the unit of $K_{L} a$ is $\min ^{-1}$. 


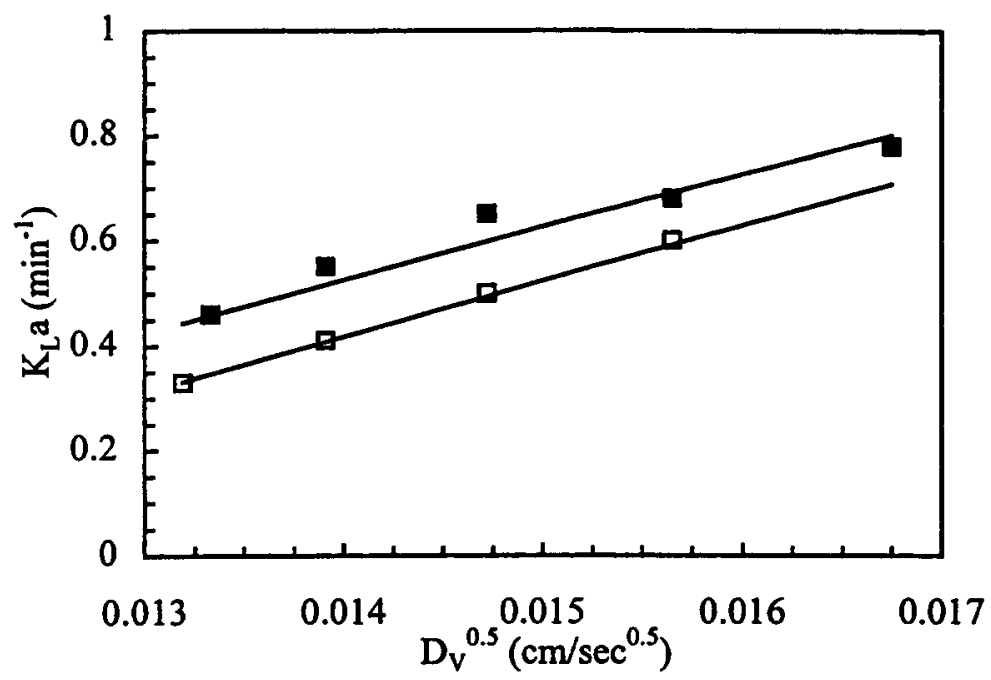

Fig. 2. Results of the linear regression of $\mathrm{K}_{\mathrm{L}} \mathrm{a}$ vs $\mathrm{D}_{\mathrm{v}}{ }^{0.5}$ at different $\mathrm{pH}$. $\square \mathrm{pH}=5.1, \mathrm{R}^{2}=0.997 ; \square \mathrm{pH}=7.2, \mathrm{R}^{2}=0.945$.

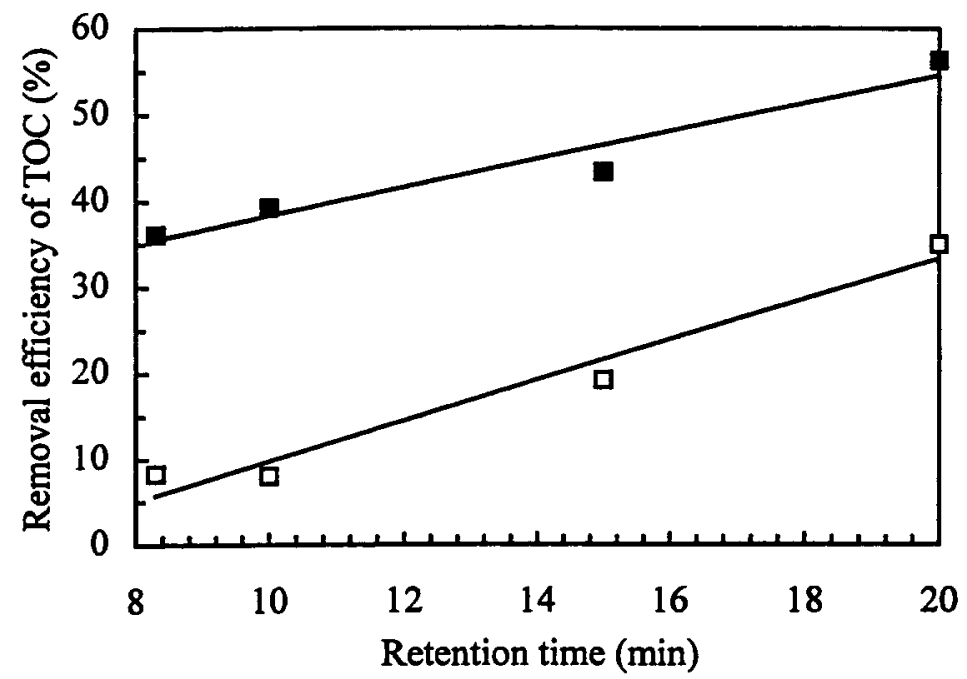

Fig. 3. Effects of retention time on TOC removal efficiency during continuous-type ozonation. $\square$ agitation speed $=100 \mathrm{rpm} ; \quad$ agitation speed $=300 \mathrm{rpm}$.

Determination of TOC reaction rate constant. According to Eq. 9, one can regulate the liquid flow rate and ozone concentration to achieve the expected level of TOC removal efficiency, if the reaction rate constant, $K$, is known. Therefore, the lab-scale ozonation experiments in the continuous type operation were conducted to measure $\mathrm{K}$. The results of TOC removal efficiency under various agitation speeds and retention time are shown in Fig. 3. This indicates that both the enhancement of retention time and agitation speed would significantly raise the TOC removal efficiency. The $\mathrm{K}$ value averaged $0.0291 \mathrm{~L} / \mathrm{mg} \cdot \mathrm{min}$, with a standard deviation of $0.0054 \mathrm{~L} / \mathrm{mg} \cdot \mathrm{min}$.

\section{Applications}

The optimum operation conditions for semi-batch experiments. First, the Henry's law constant was calculated from the available data. In Table 1, the ozone concentration in the gas phase was directly obtained by the titration method as stated in the Analytical methods section. Then, assuming the ideal gas behavior of ozone yielded the ozone partial pressure $\left(\mathrm{P}_{\mathrm{O} 3}\right)$, the average Henry's law constant was determined to be $0.380 \mathrm{kPa} \cdot \mathrm{L} / \mathrm{mg}$.

Fractional ozone absorption (FOA) is defined as the ratio of the ozone transferred to water to the ozone applied to the reactor (Gurol 1985). The following 
Table 1. Effects of ozone partial pressures on $\mathrm{K}_{\mathrm{L}} \mathrm{a},\left[\mathrm{O}_{3}\right]^{*}$ and Henry's law constant.

\begin{tabular}{|c|c|c|c|c|}
\hline $\begin{array}{l}\text { Influent gas } \\
\text { temperature } \\
\left({ }^{\circ} \mathrm{C}\right)\end{array}$ & $\begin{array}{l}\text { Ozone partial } \\
\text { pressure, } \mathrm{P}_{03} \\
(\mathrm{kPa})\end{array}$ & $\underset{\left(\mathrm{min}^{-1}\right)}{\mathrm{K}_{\mathrm{L}} \mathrm{a}}$ & $\underset{(\mathrm{mg} / \mathrm{L})}{\left[\mathrm{O}_{3}\right]^{*}}$ & $\begin{array}{c}\text { Henry's law } \\
\text { constants } \\
(\mathrm{kPa} \cdot \mathrm{L} / \mathrm{mg})^{\sharp}\end{array}$ \\
\hline 27 & 1.517 & 0.487 & 4.078 & 0.372 \\
\hline 22 & 2.212 & 0.472 & 5.712 & 0.387 \\
\hline 27 & 2.680 & 0.466 & 7.024 & 0.382 \\
\hline
\end{tabular}

equation for FOA in semi-batch operation was derived:

$$
F O A(\%)=\frac{V \times K_{L} a\left(\left[O_{3}\right]^{*}-\left[O_{3}\right]\right)}{G \times P_{03} \times 1.98 \times 10^{5}} \times 10
$$

where $\mathrm{P}_{\mathrm{O} 3}=$ ozone partial pressure, $\mathrm{kPa}$.

The value of $1.98 \times 10^{5}$ is the factor which will transfer the term of denominator into the unit of $\mathrm{mg} / \mathrm{min}$. Substitution of Eq. 12 and the Henry's law relationship into Eq. 13 yielded the following equation:

$$
\begin{gathered}
F O A(\%)= \\
\frac{\left.V x\left(1.20 x D_{v}^{0.5} n^{0.5} G^{1.18}+0.027\right)+\frac{V x\left(P_{O 3}\right.}{0.380}-\left[O_{3}\right]\right)}{G x P_{O 3} \times 1.98 \times 10^{5}} \times 100
\end{gathered}
$$

Therefore, Eq. 14 can be applied to predict the initial ozone absorption efficiency $\left(\mathrm{FOA}_{0}\right)$ in this experimental system at $\mathrm{t}=0$, that is, $\left[\mathrm{O}_{3}\right]=0$.

$$
\begin{gathered}
F O A(\%)= \\
\frac{V \times\left(1.20 \times D_{v}^{0.5} n^{0.5} G^{1.18}+0.027\right)}{75240 \times G} \times 100
\end{gathered}
$$

The effects of temperature, agitation speed, and influent gas flow rate on $\mathrm{FOA}_{0}$ and $\mathrm{K}_{\mathrm{L}} \mathrm{a}$ can be examined based on Eqs. 15 and 12. An increase in temperature increased the diffusivity of ozone in water which led to the enhancement of $K_{L}$, because $K_{L}$ is directly proportional to $D_{v}{ }^{0.5}$ based on Higbie's penetration theory (Danckwerts 1970). $\mathrm{K}_{\mathrm{L}} \mathrm{a}$ and $\mathrm{FOA}_{0}$ were increased with an increase in agitation speeds. This is attributed to the breakdown of liquid film resistance and the increase in surface renewal rates. As a result, $\mathrm{K}_{\mathrm{L}} \mathrm{a}$ increased when the influent gas flow rate was increased, due to the increase of specific interfacial surface area, a (Stankovic 1988).

Figure 4 shows the relationships between the agitation speeds and influent gas flow rates under the specific conditions of $\mathrm{K}_{\mathrm{L}} \mathrm{a}$ and $\mathrm{FOA}_{0}$. This indicates $\mathrm{FOA}_{0}$ is mainly controlled by $n$, and not by G. Figure 4 also provides the baseline information for the engineers to choose the most practical alternative among the various arrangements of $n, G$, and $K_{L}$ a to achieve the same level of $\mathrm{FOA}_{0}$. For instance, one can find the agitation speed to obtain the desired $\mathrm{FOA}_{0}$ in the water treatment plants, if the value of $\mathrm{G}$ is given.

Furthermore, power consumption $\left(\mathrm{P}_{\mathrm{g}}\right)$ should be taken into consideration for the most efficient design and operating conditions in practice. $\mathrm{P}_{\mathrm{g}}$ was calculated as follows (McCabe et al. 1985):

$$
P_{g}=\alpha N_{p} n^{3} d_{i}^{5} \rho
$$

where,

$\mathrm{P}_{\mathrm{g}}=$ power consumption with gas dispersion, watt; $\alpha=$ ratio of $\mathrm{P}_{\mathrm{g}}$ over $\mathrm{P}_{0}$, where $\mathrm{P}_{0}$ is the power consumption in ungassed liquid; and, $\mathrm{N}_{\mathrm{p}}=$ power number, $\mathrm{N}_{\mathrm{p}}=\mathrm{P}_{\mathrm{o}} / \mathrm{n}^{3} \mathrm{~d}_{\mathrm{i}}^{5} \rho$.

Since $\alpha$ is a function of superficial gas velocity which is directly proportional to $G, P_{g}$ is influenced by both $\mathbf{n}$ and $\mathrm{G}$. In addition, for a standard six-bladed turbine, $\mathrm{N}_{\mathrm{p}}=5.2$ and $\alpha$ can be calculated corresponding to various $\mathrm{G}$ values (McCabe et al. 1985). The resulting $P_{g}$ values under different $n$ and $G$ are shown in Fig. 4. This figure can be used to determine $G$ and $n$ for given requirements of $\mathrm{FOA}_{0}$ and $\mathrm{P}_{\mathrm{g}}$. Also, under a 


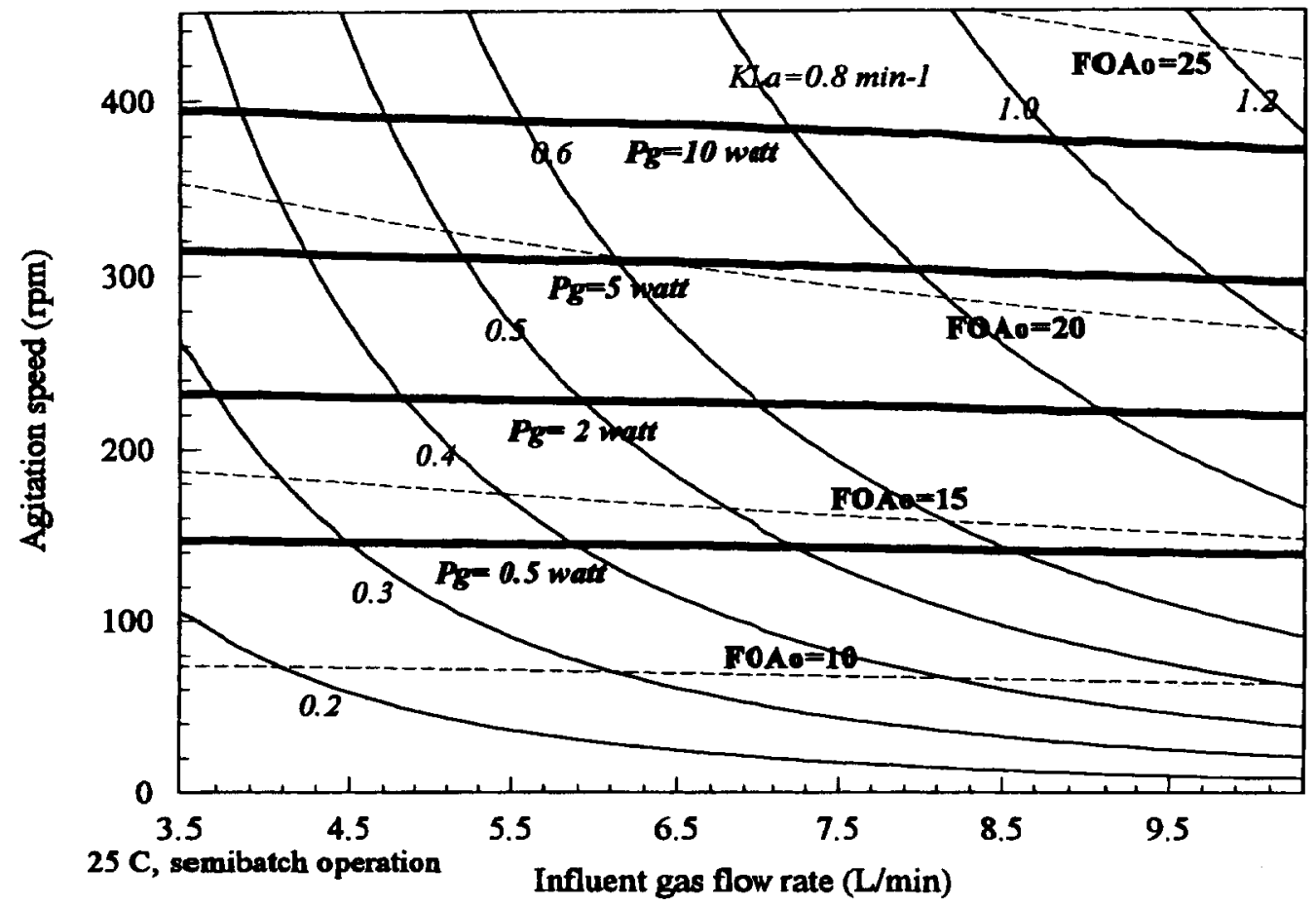

Fig. 4. The relationships between agitation speeds and influent gas flow rates under specific conditions of $\mathrm{K}_{\mathrm{L}} \mathrm{a}$, FOA 0 , and power consumption.

constant value of $\mathrm{G}$, the optimum operation conditions for semi-batch operation can be determined through the use of Fig. 4.

The optimum agitation speed for TOC removal during continuous operations. In this section, the $\mathrm{K}_{\mathrm{L}}$ a prediction model is integrated with TOC removal efficiency relationship, to develop the ozone mass transfer model in view of controlling the formation of organic compounds. Based on mass balance of dissolved ozone concentration in reactor during continuous-type operation, the following equation can be derived:

$$
V \frac{d\left[O_{3}\right]}{d t}=V \times K_{L} a\left(\left[O_{3}\right]^{*}-\left[O_{3}\right]\right)-V r_{O 3}-Q
$$

where $\mathrm{r}_{\mathrm{O} 3}=$ reaction rate of ozone, $\mathrm{mg} / \mathrm{L} \cdot \mathrm{min}$, = $\mathrm{K}[\mathrm{TOC}]\left[\mathrm{O}_{3}\right]$, as shown in Eq. 7 .

For steady state condition, Eq. 17 becomes:

$$
\mathrm{Q}\left[\mathrm{O}_{3}\right]=\mathrm{V} \times \mathrm{K}_{\mathrm{L}} \mathrm{a}\left(\left[\mathrm{O}_{3}\right]^{*}-\left[\mathrm{O}_{3}\right]\right)-\mathrm{Vr}_{\mathrm{O} 3}
$$

If $\left[\mathrm{O}_{3}\right]^{*}$ is replaced by the ozone partial pressure, $\mathrm{P}_{\mathrm{O}}$, Eq. 18 can be modified as:

$$
Q\left[O_{3}\right]=V \times K_{L} a\left(\frac{P_{O 3}}{0.380}-\left[O_{3}\right]\right)-V r_{O}
$$

Since the prediction model of $\mathrm{K}_{\mathrm{L}} \mathrm{a}$ (Eq. 12) is applicable only to the deionized water, it is necessary to introduce the enhancement factor, $\mathbf{E}$, to account for the effect of organic compounds in the real water sample on $K_{1} a$ :

$$
E=\frac{K_{L} a \text { with reaction }}{K_{L} a \text { without reaction }}
$$

For the fixed level of water quality parameters, applied ozone concentration, and influent gas flow rate, the following equations were developed by combining Eqs. 12, 19, and 20: 


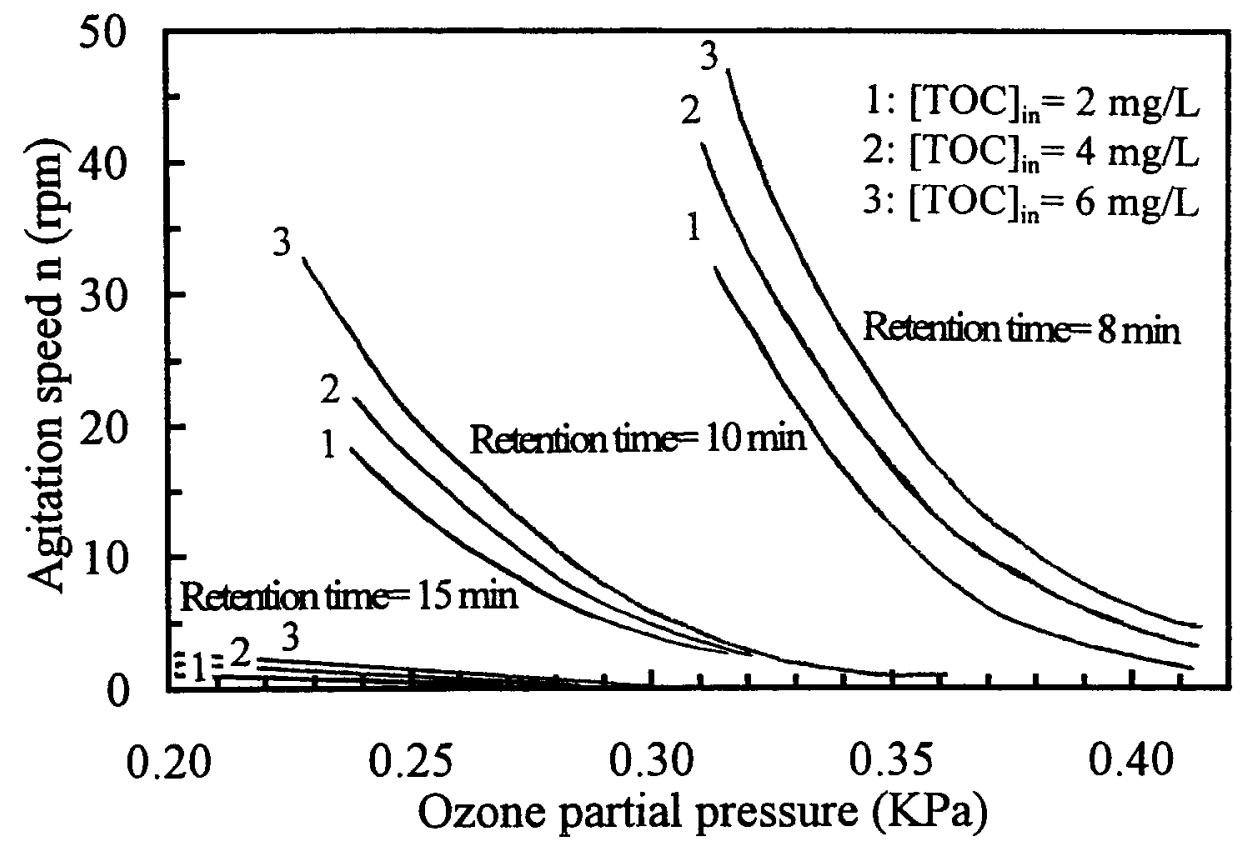

Fig. 5. Simulation results of the relationship between agitation speed and ozone partial pressure in the view of controlling the formation of TOC.

$n=\left(\frac{Q\left[O_{3}\right]+V r_{O 3}}{1.20 x \boldsymbol{E} V\left(\frac{P_{O 3}}{0.380}-\left[O_{3}\right]\right)}-0.0225\right)^{2} D_{v}^{-1} G^{-2.36}$

where the unit of $\mathrm{n}$ is rps.

Equation 21 includes the mass transfer and reaction kinetics characterizations and can be successfully used in predicting the most efficient agitation speed for controlling the formation of organic compounds in the ozonation process. Also, the marginal level of ozone partial pressure to achieve the highest TOC removability can be determined through the use of the above developed model (Eq. 21). For example, Fig. 5 gives the relationship between the agitation speed and applied ozone concentration under various retention times. In this simulation study, the temperature $\left(25^{\circ} \mathrm{C}\right)$, $\mathrm{pH}(7)$, influent gas flow rate $(10 \mathrm{~L} / \mathrm{min})$, the removal efficiency of TOC (15\%), and enhancement factor $(\mathbf{E}=1)$ were held constant. The higher the ozone partial pressure, the lower the agitation speed needed to achieve the same level of performance. In other words, it is only necessary to increase the ozone partial pressure slightly, instead of greatly enhancing the agitation power consumption, to obtain the same level of removal efficiency of TOC.

\section{CONCLUSIONS}

The prediction model of $\mathrm{K}_{\mathrm{L}}$ a was developed through the use of dimensional analysis. Substitution of laboratory data into the $\mathrm{K}_{\mathrm{L}}$ a prediction model showed that overall mass transfer coefficient is a function of diffusivity, agitation speed, and gas flow rate, and the parameters in the equation were determined.

Based on the mass balance relationship and kinetic expression of TOC oxidation, an equation governing TOC removal efficiency during the continuous experiments was developed. The $\mathrm{K}$ value averaged $0.0291 \mathrm{~L} / \mathrm{mg} \cdot \mathrm{min}$, with a standard deviation of $0.0054 \mathrm{~L} / \mathrm{mg} \cdot \mathrm{min}$.

The relationships between agitation speeds and influent gas flow rates under specific conditions of $\mathrm{K}_{\mathrm{L}} \mathrm{a}, \mathrm{FOA}_{0}$, and power consumption were developed as shown in Fig. 4. Figure 4 can provide the baseline information for the engineers to choose the most practical alternative among the various combinations of $n, G$, $\mathrm{K}_{\mathrm{L}} \mathrm{a}$, and $\mathrm{P}_{\mathrm{g}}$ to achieve the same level of $\mathrm{FOA}_{0}$.

The developed model in combination with mass transfer and reaction kinetics can be used successfully in predicting the most efficient agitation speed for controlling the formation of organic compounds. Also, the critical value of ozone partial pressure to achieve the highest TOC removability can be determined 
through the use of the above developed model. For example, it is only necessary to increase ozone partial pressure slightly, instead of greatly enhancing the agitation power consumption, to achieve the same level of removal efficiency of TOC.

\section{REFERENCES}

Bader, H.; Hoigne, J. Determination of ozone in water by the indigo method. Water Res. 15: 449-456; 1981.

Benitez, F.J.; Beltran-Heredia, J.; Gonzalez, T. Kinetics of the reaction between ozone and MCPA. Water Res. 25: 1345-1349; 1991.

Danckwerts, P.V. Gas-liquid reactions. New York, NY: McGrawHill; 1970.

Grasso, D. Ozonation of drinking water: A design methodology II mass transfer and contacting. Ozone Sci. Eng. 9: 125-140; 1987.
Gurol, M.D. Factors controlling the removal of organic pollutants in ozone reactors. J. Am. Water Wks. Assoc. 77: 55-60; 1985.

McCabe, W.L.; Smith, J.C.; Harriott, P. Unit operations of chemical engineering. 4th ed. New York, NY: McGraw-Hill; 1985.

Ouederni, A.; Mora, J.C.; Bes, R.S. Ozone absorption in water: Mass transfer and solubility. Ozone Sci. Eng. 9: 1-12; 1987.

Roth, J.A.; Moench, W.L.; Debalak, K.A. Kinetic modeling of the ozonation of phenol in water. J. Water Pollut. Control Fed. 54: 135-139; 1982.

Sheffer, S.; Esterson, G.L. Mass transfer and reaction kinetics in the ozone/tap water system. Water Res. 10: 383-389; 1982.

Sotelo, J.L.; Beltran, F.J.; Benitez, F.J.; Beltran-Heredia, J. Henry's law constants for the ozone-water system. Water Res. 23: 1239$1246 ; 1989$.

Stankovic, I. Comparison of ozone and oxygen mass transfer in a laboratory and pilot plant operation. Ozone Sci. Eng. 10: 321$338 ; 1988$.

Yang, Y.M. Effects of ozone mass transfer on the formation and control of volatile organic compounds in drinking water. Master's Thesis. Taipei: Graduate Institute of Environmental Engineering, National Taiwan University; 1991. (In Chinese) 